\title{
Molecular and immunological tools for the evaluation of the cellular immune response in the neotropical monkey Saimiri sciureus, a non-human primate model for malaria research
}

Evelyn KP Riccio 1,2, Lilian R Pratt-Riccio ${ }^{1,2}$, Cesare Bianco-Júnior ${ }^{1,2}$, Violette Sanchez ${ }^{1,2,3}$, Paulo RR Totino 1,2, Leonardo JM Carvalho ${ }^{1,2}$ and Cláudio Tadeu Daniel-Ribeiro ${ }^{1,2^{*}}$

\begin{abstract}
Background: The neotropical, non-human primates (NHP) of the genus Saimiri and Aotus are recommended by the World Health Organization as experimental models for the study of human malaria because these animals can be infected with the same Plasmodium that cause malaria in humans. However, one limitation is the lack of immunological tools to assess the immune response in these models. The present study focuses on the development and comparative use of molecular and immunological methods to evaluate the cellular immune response in Saimiri sciureus.

Methods: Blood samples were obtained from nineteen uninfected Saimiri. Peripheral blood mononuclear cells (PBMC) from these animals and splenocytes from one splenectomized animal were cultured for 6, 12, 18, 24, 48, 72 and 96 hrs in the presence of phorbol-12-myristate-13-acetate and ionomycin. The cytokine levels in the supernatant were detected using human and NHP cytometric bead array Th1/Th2 cytokine kits, the Bio-Plex Pro Human Cytokine Th1/Th2 Assay, enzyme-linked immunosorbent assay, enzyme-linked immunospot assays and intracellular cytokine secretion assays. Cytokine gene expression was examined through TaqMan ${ }^{\circledR}$ Gene Expression Real-Time PCR using predesigned human gene-specific primers and probes or primers and probes designed based on published S. sciureus cytokine sequences.

Results: The use of five assays based on monoclonal antibodies specific for human cytokines facilitated the detection of IL-2, IL-4 and/or IFN- $-\gamma$. TaqMan array plates facilitated the detection of 12 of the 28 cytokines assayed. However, only seven cytokines (IL-1A, IL-2, IL-10, IL-12B, IL-17, IFN- $\beta$, and TNF) presented relative expression levels of at least 70\% of the gene expression observed in human PBMC. The use of primers and probes specific for S. sciureus cytokines facilitated the detection of transcripts that showed relative expression below the threshold of $70 \%$. The most efficient evaluation of cytokine gene expression, in PBMC and splenocytes, was observed after 6-12 hrs of culture, except for LTA in PBMC, whose expression was best analysed after 24 hrs of culture.
\end{abstract}

Conclusions: Real-time PCR facilitates the analysis of a large number of cytokines altered during malaria infection, and this technique is considered the best tool for the evaluation of the cellular immune response in S. sciureus.

Keywords: Saimiri sciureus, Immune response, Malaria, Cytokines, Cellular response

\footnotetext{
* Correspondence: malaria@fiocruz.br

'Laboratório de Pesquisa em Malária, Instituto Oswaldo Cruz, Fiocruz,

Avenida Brasil 4365, Pavilhão Leônidas Deane, Salas 513-517, $5^{\circ}$ andar

Manguinhos, Rio de Janeiro, RJ CEP: 21040-900, Brazil

${ }^{2}$ Centro de Pesquisa, Diagnóstico e Treinamento em Malária (CPD-Mal), Fiocruz,

Reference Centre for Malaria in the Extra-Amazonian Region for the Secretary for

Health Surveillance, Ministry of Health, Rio de Janeiro, RJ, Brazil

Full list of author information is available at the end of the article
} 


\section{Background}

Research involving non-human primates (NHP) has played a critical role in many of the medical and scientific advances in the last decade. NHP are used because of the similarities of these animals to humans in terms of physiology, neuroanatomy, reproduction, development, cognition, and social complexity. The close phylogenetic relationship of NHP to humans also makes these animals excellent models for the study of a range of biological phenomena. These similarities between humans and NHP suggest that there is greater validity of the data obtained from primate models compared to other animal models, and experiments conducted using these models might address questions that cannot be addressed using other species.

For several infectious diseases, NHP are the only animal species susceptible to the infectious agent that threatens human populations, and proof-of-concept of candidate vaccines can therefore only be studied in these species. The choice of the NHP model depends on the nature of the pathogen. Hepatitis virus has a host range restricted to humans and some NHP, including Callithrix jaccus, Macaca mulatta, Macaca fascicularis and chimpanzee, making these models valuable for studies on hepatitis [1-5]. In AIDS research, NHP are used to investigate the mechanisms underlying immune system regulation and disease pathogenesis and to optimize immunization strategies and vaccine safety and immunogenicity [6-8]. Other infectious agents for which NHP have been valuable for vaccine research include influenza virus, Trypanosoma cruzi, Mycobacterium, flavivirus, poliovirus, Bacillus anthracis, Helicobacter pylori, Ebola virus, and Plasmodium species [9].

Experimental models have been used from the inception of malariology and have provided important insights into the mechanisms underlying Plasmodium diseases $[10,11]$. Many studies on malaria have used rodent or NHP experimental models, which have been long-standing tools for malaria immunology and pathogenesis studies [12]. There is, however, no animal model as reliable as the NHP for studying the basic mechanisms of human diseases [13]. In addition, recent studies have reported the natural infection of NHP, such as bonobos and chimpanzees, with human Plasmodium or plasmodial ancestors [14-16].

The NHP of the genera Aotus and Saimiri are the experimental models recommended by the World Health Organization for research in malaria [17-20] because these NHP develop a reproducible parasitaemia when inoculated with the blood stages or even sporozoites of the human plasmodial species Plasmodium falciparum and Plasmodium vivax, making these animals particularly useful in preclinical trials of potential malaria vaccines and for studies on pathogenesis [21-25]. In addition, strains adapted to NHP have been used in studies to test schizonticidal anti-malarial drugs, malaria vaccine studies examining both pre-erythrocytic candidate antigens and transmission-blocking vaccines and $P$. vivax biology and genetic studies in both invertebrate mosquito vectors and primate vertebrate hosts [26,27]. Preclinical evaluation in these experimental models can provide valuable information on the immunogenicity, efficacy and safety of a variety of formulations, facilitating a more refined selection of the most appropriate formulations for evaluation in humans.

Although the NHP model might offer many advantages for the study of malaria, one important limitation is the lack of specific reagents and immunological tools for the reliable evaluation of primate immune responses. In some cases, immunological reagents for human molecules can be used, although sensitivity is typically low $[28,29]$. Few cytokine studies have been performed in Saimiri [30-32], although research efforts have been focused on sequencing individual cytokine genes of interest. Moreover, researchers have also attempted to develop molecular tools to measure the mRNA expression of IL-2, IL-5, IL-6, IL-10, IL-12, LTA, TNF, and IFN- $\gamma$ $[30,33]$. The present study focused on the development and comparative use of molecular and immunological methods to monitor the cellular immune response in Saimiri sciureus monkeys, with the aim of providing information for future immunization studies involving $P$. falciparum vaccine candidates.

\section{Methods}

\section{Animals and legal bioethics aspects}

Nineteen clinically healthy NHP of the Saimiri sciureus species from the breeding colony at the Department of Primatology (CECAL)/Fiocruz in Rio de Janeiro, Brazil were sampled and used in different assays. These animals were young, ranging between four and eight years of age. The experiments involving Saimiri were reviewed and approved through the Ethics Committee on Animal Use of Fiocruz (CEUA, Fiocruz, Rio de Janeiro, Brazil protocol P-391/07) and conducted in accordance with the requirements of the laboratory biosafety rules (License $n^{\circ}$ L-0062/08).

\section{Tissue sampling, isolation and culture of cells}

The animals were anaesthetized with a combination of $0.1 \mathrm{ml}$ midazolan and $0.4 \mathrm{ml}$ ketamine. Blood samples were collected via femoral venipuncture, and cells were obtained from $4 \mathrm{ml}$ heparinized venous samples obtained from each individual. The peripheral blood mononuclear cells (PBMC) were separated through density gradient centrifugation using Ficoll-Hypaque (Sigma), washed twice in phosphate-buffered saline (PBS) (Sigma), resuspended and cultured in RPMI medium containing $15 \mathrm{mM}$ glutamine (Gibco), $10 \mathrm{mM}$ Hepes, $200 \mathrm{U} / \mathrm{ml}$ penicillin (Gibco), 
$200 \mu \mathrm{g} / \mathrm{ml}$ streptomycin (Gibco), $3 \mathrm{mg} / \mathrm{ml}$ gentamicin (Sigma) and $2 \mathrm{~g} / \mathrm{l}$ sodium bicarbonate (Sigma) supplemented with $10 \%$ inactivated foetal calf serum (FCS) (Imunoquímica). The cells $\left(2.5 \times 10^{5}\right.$ cells/well $)$ were activated with a combination of 50-100 $\mathrm{ng} / \mathrm{ml}$ phorbol 12-myristate 13-acetate (PMA-Sigma) and 250-500 ng/ml ionomycin (Sigma) and cultured at $37^{\circ} \mathrm{C}$ in $5 \% \mathrm{CO}_{2}$. The cells and supernatant were collected after 6, 12, 18, 24, 48, 72 and 96 hrs. Subsequently, the cells were resuspended in RNAlater solution (Ambion Life Technologies), incubated at $4^{\circ} \mathrm{C}$ overnight and subsequently stored at $-20^{\circ} \mathrm{C}$ until RNA extraction for the analysis of gene expression using real-time PCR. The supernatant was stored at $-80^{\circ} \mathrm{C}$ prior to the detection and quantification of $\mathrm{cy}$ tokines. In all experiments, human blood samples from two healthy donors from the Laboratory for Malaria Research were collected and used as control.

One naive Saimiri monkey (PA51) was splenectomized, and the splenocytes were used in cellular assays. A trained veterinarian performed the splenectomy using ketamine $(150 \mathrm{mg} / \mathrm{kg})$ and xylazine $(10 \mathrm{mg} / \mathrm{kg})$ for anaesthesia in an aseptic surgical room. After spleen removal and vascular resection, the wound was sutured, and the animal was allowed to recover under the close supervision of trained staff. Immediately after removal, a piece of the spleen was conditioned in sterile RPMI 1640 medium supplemented with 10\% FCS and gently fragmented using a cell strainer. The splenocytes were washed with RPMI 1640 medium supplemented with $10 \%$ FCS, and $3 \mathrm{ml}$ of erythrocyte lysis buffer was added to the pellet and incubated for $5 \mathrm{~min}$ at $37^{\circ} \mathrm{C}$. The splenocytes were cultured in vitro under mitogenic stimulus with PMA (Sigma) and ionomycin (Sigma) as previously described. The cells were collected after $6,12,18,24,48,72$ and 96 hrs of culture, resuspended in RNAlater solution (Ambion Life Technologies), incubated at $4^{\circ} \mathrm{C}$ overnight and subsequently stored at $-20^{\circ} \mathrm{C}$ prior to RNA extraction for the analysis of gene expression using real-time PCR.

\section{Cytometric bead array (CBA)}

The cytokine levels were assessed using two BD Cytometric Bead Array (CBA) Th1/Th2 Cytokine Kits (BD Bioscience). One human kit for the detection of IL-2, IL-4, IL-6, IL-10, TNF and IFN- $\gamma$ and other NHP kit (rhesus, cynomolgus, baboon, or pigtailed macaque non-human primate species) for the simultaneous detection of six cytokines (IL-2, IL-4, IL-5, IL-6, TNF and IFN- $\gamma$ ) in the supernatant of PBMC cultures.

Samples from two Saimiri (V17 and V31) were used for the evaluation of human CBA kit and samples from three Saimiri (S8, S34 e S36) for the evaluation of NHP CBA kit. Blood samples obtained from one human healthy donor were used as control. The cytokine levels were determined in the test samples according to the manufacturer's instructions. Briefly, $25 \mu \mathrm{l}$ of the supernatant obtained from PBMC cultures was incubated for $2 \mathrm{hrs}$ at room temperature (RT) with $25 \mu \mathrm{l}$ of cytokine capture beads and $25 \mu \mathrm{l}$ of PE detection reagent. After incubation, the samples were washed once with washing buffer. The supernatants were discarded, and the pellets were resuspended in $300 \mu \mathrm{l}$ of washing buffer for analysis on a FACS Calibur flow cytometer (Becton Dickinson). The concentration of each cytokine in $\mathrm{pg} / \mathrm{ml}$ was determined based on a standard curve generated using the recombinant cytokines provided in the kit. In human CBA kit, the lower limits of detection for IL-2, IL-4, IL-6, IL-10, TNF and IFN- $\gamma$ were $2.6,2.6,3.0,2.8,2.8$ and $7.1 \mathrm{pg} / \mathrm{ml}$, respectively, while in NHP CBA kit, the lower limits of detection for IL-2, IL-4, IL-5, IL-6, TNF and IFN- $\gamma$ were 3.6, 0.9, 0.3, $0.1,0.4,3.3 \mathrm{pg} / \mathrm{ml}$, respectively.

\section{Luminex - Th1/Th2 cytokine quantification in supernatant cultures}

The Bio-Plex Pro Human Cytokine Th1/Th2 Assay (BioRad Laboratories, Inc) containing fluorescent microspheres conjugated to monoclonal antibodies specific to Th1- and Th2-related cytokines, including IL-2, IL-4, IL-5, IL-10, IL-12, IL-13, GM-CSF, IFN- $\gamma$, and TNF, was used.

The cytokine levels in the supernatants of PBMC cultures were analysed according to the manufacturer's instructions. Briefly, a $50 \mu \mathrm{l}$ sample obtained from one human and two Saimiri (V17 e V31) samples was diluted 1:4 with sample diluent, incubated with antibodycoupled beads and washed. Subsequently, the samples were incubated with biotinylated secondary antibodies, followed by incubation with streptavidin-phycoerythrin. The beads were read on a Luminex System (Bioplex 200, Bio-Rad). The standard curves were generated with a dynamic range between 5 and 20,000 pg/ml, and the data were analysed using Bioplex Manager Software.

A serial dilution of the standards was added to the plate in duplicate to obtain a standard curve. Following the generation of a five-parameter logistic curve, the standard recovery was calculated using the following equation: (observed concentration/expected concentration) $\times 100$. A recovery range between 80 and 120\% was used according to the manufacturer's recommendations. Any sample with a standard recovery value in an area of the curve outside of this range was not considered accurate, and samples were considered positive if the values obtained were above the limits of detection for IL-2, IL-4, Il-5, IL-10, IL-12, IL-13, GM-CSF, IFN- $\gamma$ and TNF that were 0.003, 0.001, 0.01, $0.006,0.01,0.009,0.004,0.008$ and $0.03 \mathrm{pg} / \mathrm{ml}$, respectively, in accordance with the manufacturer's recommendations. 


\section{Enzyme-linked immunospot (ELISPOT) cytokine measurements}

Several antibodies were used to determine the levels of different cytokines in the culture supernatant, in accordance with methodology previously described [34]. The monoclonal antibodies used in the ELISPOT assays are listed in Table 1.

Blood samples from eight Saimiri sciureus (U1, R1, O13, O17, Q3, Q7, J3 and J7) and from one clinically healthy human donor were used in ELISPOT assays.

MultiScreen-IP 96-well plates (Millipore) were coated at $4^{\circ} \mathrm{C}$ overnight with $100 \mu \mathrm{l}$ of cytokine monoclonal antibody at a concentration of $8 \mu \mathrm{g} / \mathrm{ml}$ in filtered carbonate-bicarbonate buffer $(\mathrm{pH} 9.6)$. The plates were subsequently washed three times with sterile PBS, and the uncoated sites were blocked with $200 \mu \mathrm{l}$ of PBS containing 10\% FCS (Imunoquímica) for $2 \mathrm{hrs}$ at $37^{\circ} \mathrm{C}$ in $5 \%$ $\mathrm{CO}_{2}$. Approximately $2 \times 10^{5}$ cells/well were transferred to each precoated well and stimulated for $18 \mathrm{hrs}$ with $50 \mathrm{ng} / \mathrm{ml}$ PMA (Sigma) and $250 \mathrm{ng} / \mathrm{ml}$ ionomycin (Sigma) in complete RPMI 1640 medium containing $15 \mathrm{mM}$ glutamine (Sigma), $10 \mathrm{mM}$ Hepes, $200 \mathrm{U} / \mathrm{ml}$ penicillin (Sigma), $200 \mu \mathrm{g} / \mathrm{ml}$ streptomycin (Sigma), $3 \mathrm{mg} / \mathrm{ml}$ gentamicin (Sigma) and $2 \mathrm{~g} / \mathrm{l}$ sodium bicarbonate (Grupo Química) and supplemented with 10\% inactivated FCS (Imunoquímica). After three washes with $\mathrm{PBS}$ and three washes with PBS/0.05\% Tween 20 (PBS/T20 washing buffer), $100 \mu \mathrm{l}$ of $1 \mu \mathrm{g} / \mathrm{ml}$ diluted biotinylated antibody was added. The plates were incubated for $1 \mathrm{hr}$ at RT and subsequently washed three times with washing buffer. Streptavidin conjugated to horseradish peroxidase (BD Bioscience) was diluted 1:1000 in washing buffer, and $100 \mu \mathrm{l}$ of this dilution was added to each well. The plates were incubated for $1 \mathrm{hr}$ at RT, followed by washing three times with washing buffer and three times with PBS. The plates were developed using the AEC Substrate Kit (BD Bioscience)

Table 1 Commercially available human-specific antibodies tested for reactivity with Saimiri cytokines in ELISA and ELISPOT assays

\begin{tabular}{|c|c|c|c|c|c|}
\hline \multirow{2}{*}{$\begin{array}{l}\text { Anti-human } \\
\text { mAbs }\end{array}$} & \multirow[t]{2}{*}{ Clones } & \multirow[t]{2}{*}{ Suppliers } & \multirow[t]{2}{*}{ References } & \multicolumn{2}{|c|}{ Reactivity } \\
\hline & & & & Human & Saimiri \\
\hline IFN- $\gamma$ capture & mAb GZ-4 & Mabtech & $3420 \mathrm{M}-3$ & + & + \\
\hline IFN- $\gamma$ biotin & mAb 7-B6- & Mabtech & $3420-6$ & + & + \\
\hline IFN- $\gamma$ capture & B27 & BD Bioscience & 18891D & + & - \\
\hline IFN- $\gamma$ biotin & 4SB3 & BD Bioscience & 554550 & + & - \\
\hline IL-4 capture & 8D4-8 & BD Bioscience & 554515 & - & - \\
\hline IL-4 biotin & MP4-25D2 & BD Bioscience & 18502D & - & - \\
\hline IL-4 capture & mAb IL4-I & Mabtech & $3410-3$ & + & + \\
\hline IL-4 biotin & mAb IL4-II & Mabtech & $3410-6$ & + & + \\
\hline IL-5 capture & TRFK5 & BD Bioscience & 554393 & + & - \\
\hline IL-5 biotin & JES1-5A10 & BD Bioscience & 554491 & + & - \\
\hline IL-5 capture & mAb TRFK-5 & Mabtech & $3490-3$ & + & - \\
\hline IL-5 biotin & mAb 5 A10 & Mabtech & $3490-6$ & + & - \\
\hline IL-10 capture & JES3-9D7 & BD Bioscience & 554497 & - & - \\
\hline IL-10 biotin & JES3-12G8 & BD Bioscience & 554499 & - & - \\
\hline IL-10 capture & 2617Kla & BD Bioscience & 51-26171E & + & - \\
\hline IL-10 biotin & $2617 \mathrm{Klb}$ & BD Bioscience & $51-26172 E$ & + & - \\
\hline IL-10 capture & mAb 9D7 & Mabtech & $3430-3$ & + & - \\
\hline IL-10 biotin & mAb 12 G8 & Mabtech & $3430-6$ & + & - \\
\hline IL-10 capture & 945A5D11 & Biosource & AHC8102 & + & - \\
\hline IL-10 biotin & $945 \mathrm{~A} 5 \mathrm{~A} 10$ & Biosource & AHC7109 & + & - \\
\hline IL-13 capture & mAb IL13 I & Mabtech & $3470-3$ & + & - \\
\hline IL-13 biotin & mAb IL13 & Mabtech & $3470-6$ & + & - \\
\hline TNFcapture & mAb1 & BD Bioscience & 554509 & + & - \\
\hline TNF biotin & mAb11 & BD Bioscience & $18642 \mathrm{D}$ & + & - \\
\hline TNFcapture & 2637Kla & BD Bioscience & 555212 & + & - \\
\hline TNF biotin & $2637 \mathrm{Klb}$ & BD Bioscience & 555212 & + & - \\
\hline
\end{tabular}


comprising $30 \mathrm{ml}$ of AEC chromogen solution with 25 drops of AEC substrate. One-hundred $\mu \mathrm{l}$ of the substrate was added to each well, and the plate was incubated until red spots emerged (10-15 min). Colour development was terminated using washing buffer. The plates were air-dried, and the spot numbers were counted using an Immunospot Series 3B Analyzer (Cellular Technology). The spot count in unstimulated, negative control wells was subtracted from that in the test wells. The mean number of spot-forming units (SFU) in the paired wells was multiplied by four to obtain the SFU per $10^{6} \mathrm{PBMC}$. Counts $\geq 20 \mathrm{SFU} / 10^{6} \mathrm{PBMC}$ and at least $\geq$ two-fold greater than the background counts were considered positive responses.

\section{Enzyme-linked immunosorbent assay (ELISA)}

ELISA was performed using the same pairs of monoclonal antibodies (Table 1) and blood samples obtained from three Saimiri sciureus (B11, J7 and N5) and from one human donor were used in ELISA assay. Briefly, 96well, flat-bottomed microtitre plates (Nunc) were coated with $100 \mu \mathrm{l}$ of anti-human monoclonal cytokine detection antibodies at $4 \mu \mathrm{g} / \mathrm{ml}$ (diluted in $0.1 \mathrm{M} \mathrm{NaHCO}_{3}$ ). After overnight incubation at $4^{\circ} \mathrm{C}$, the plates were washed three times with sterile PBS, and the uncoated sites were blocked with $200 \mu \mathrm{l}$ of PBS containing 10\% FCS for $2 \mathrm{hrs}$ at $37^{\circ} \mathrm{C}$. After subsequent washing, $100 \mu \mathrm{l}$ of the supernatant obtained from the culture samples was added to duplicate wells, and the plates were incubated for $2 \mathrm{hrs}$ at $37^{\circ} \mathrm{C}$. The plates were subsequently washed, and $100 \mu \mathrm{l}$ of biotinylated anti-human cytokine detection antibody at $1 \mu \mathrm{g} / \mathrm{ml} \mathrm{(1/250} \mathrm{dilution)} \mathrm{and}$
$100 \mu \mathrm{l}$ of streptavidin peroxidase at $2.5 \mu \mathrm{g} / \mathrm{ml} .(1 / 250 \mathrm{di}-$ lution) were added. After incubation for $1 \mathrm{hr}$ at $37^{\circ} \mathrm{C}$ and additional washing, $100 \mu \mathrm{l} /$ well of orthophenylediamine (OPD) in citrate-phosphate buffer $(10 \mathrm{mg} / 25 \mathrm{ml}$ plus $10 \mathrm{ml} \mathrm{H}_{2} \mathrm{O}_{2}$ ) ( $\mathrm{pH} \mathrm{5.0)}$ was added to each well and incubated for $30 \mathrm{~min}$ at $\mathrm{RT}$ in the dark, followed by the addition of $50 \mu \mathrm{l} /$ well $2 \mathrm{~N} \mathrm{H}_{2} \mathrm{SO}_{4}$ to terminate the reaction. The absorbance was read at $405 \mathrm{~nm}$ using a spectrophotometer (Spectra Max 250; Molecular Devices). A standard curve was constructed for each cytokine using different dilutions of human recombinant cytokines.

\section{Intracellular cytokine secretion (ICS)}

Immune cell activation was also determined according to the percentage of cells producing cytokines after in vitro stimulation. Blood samples from one Saimiri (B11) and from one human donor were used for the evaluation of ICS. Briefly, $1 \times 10^{6}$ purified $\mathrm{PBMC} / \mathrm{ml}$ were cultured in complete RPMI-1640 medium containing $15 \mathrm{mM}$ glutamine (Sigma), $10 \mathrm{mM}$ Hepes, $200 \mathrm{U} / \mathrm{ml}$ penicillin (Sigma), $200 \mu \mathrm{g} / \mathrm{ml}$ streptomycin (Sigma), $3 \mathrm{mg} / \mathrm{ml}$ gentamicin (Sigma), and $2 \mathrm{~g} / \mathrm{l}$ sodium bicarbonate (Grupo Química) and supplemented with 10\% inactivated FCS (Imunoquímica) on 24-well plates and incubated for $24 \mathrm{hrs}$ at $37^{\circ} \mathrm{C}, 5 \% \mathrm{CO}_{2}$. Cells were either cultured in the presence of $100 \mathrm{ng} / \mathrm{ml} \mathrm{PMA} \mathrm{(Sigma)} \mathrm{and} 500 \mathrm{ng} / \mathrm{ml}$ ionomycin (Sigma) or in the absence of mitogen. To block cytokine secretion, the protein transport inhibitor brefeldin A ( $2.5 \mu \mathrm{g} / \mathrm{ml}-$ BD Bioscience) was added to all samples after $12 \mathrm{hrs}$ of culture. After $24 \mathrm{hrs}$, the cells were harvested and washed with PBS. Another incubation with $100 \mu \mathrm{l}$ of

Table 2 Commercially available human-specific antibodies tested for reactivity with Saimiri cytokines in ICS assays

\begin{tabular}{|c|c|c|c|c|c|}
\hline Reagents & Clones & Suppliers & References & Human & Saimiri \\
\hline IFN- $\gamma$ capture & $m A b$ GZ-4 & Mabtech & $m A b$ GZ-4 & + & + \\
\hline IFN- $\gamma$ biotin & mAb 7-B6-1 & Mabtech & mAb 7-B6-1 & + & + \\
\hline IFN- $\gamma$ capture & B27 & BD Bioscience & 18891D & + & - \\
\hline IFN- $\gamma$ biotin & 4SB3 & BD Bioscience & 554550 & + & - \\
\hline IL-4 capture & 8D4-8 & BD Bioscience & 554515 & - & - \\
\hline IL-4 biotin & MP4-25D2 & BD Bioscience & $18502 D$ & - & - \\
\hline IL-5 capture & TRFK5 & BD Bioscience & 554393 & + & - \\
\hline IL-5 biotin & JES1-5A10 & BD Bioscience & 554491 & + & - \\
\hline IL-10 capture & JES3-9D7 & BD Bioscience & 554497 & - & - \\
\hline IL-10 biotin & JES3-12G8 & BD Bioscience & 554499 & - & - \\
\hline IL-10 capture & 945A5D11 & Biosource & AHC8102 & - & - \\
\hline IL-10 biotin & 945A5A10 & Biosource & AHC7109 & - & - \\
\hline IL-13 capture & mAb IL13-I & Mabtech & $3470-3$ & + & - \\
\hline IL-13 biotin & mAb IL13-II & Mabtech & $3470-6$ & + & - \\
\hline TNF capture & mAb1 & BD Bioscience & 554509 & + & - \\
\hline TNF biotin & mAb11 & BD Bioscience & $18642 \mathrm{D}$ & + & - \\
\hline
\end{tabular}


permeabilization solution (PBS/0.2\% saponin/10\% FCS/1\% bovine serum albumin (BSA) was performed at RT. After centrifugation at 1,500 rpm for $10 \mathrm{~min}$, the cells were subsequently incubated for $30 \mathrm{~min}$ at RT with anti-human monoclonal cytokine detection or capture antibodies (Table 2) previously diluted in permeabilization solution. After two washes with PBS/10\% FCS/1\% BSA, the cells were incubated for $30 \mathrm{~min}$ with anti-mouse IgG FITClabeled in permeabilization solution. The cells were washed twice with PBS $/ 0.2 \%$ saponin and once with PBS and then resuspended in $2 \%$ paraformaldehyde. The experiments were analysed using a FACSCalibur flow cytometer (FACSCalibur, BD Biosciences). Over 100,000 lymphocyte-gated events were collected.

\section{Analysis of gene expression using TaqMan Array Human} Cytokine Assays for real-time PCR

The gene expression of IL-1, IL-2, IL-3, IL-4, IL-5, IL-6, IL-8, IL9, IL-10, IL-12, IL-13, IL-15, IL-16, IL-17, IL-18, IFN- $\alpha$, IFN- $\beta$, IFN- $\gamma$, LTA, TNF, the $18 \mathrm{~S}$ control, and three candidate endogenous control genes (GAPDH, HPRT1 and GUSB) was assessed through real-time PCR using TaqMan $^{\oplus}$ Gene Expression Array Plates (Applied Biosystems) containing predesigned, gene-specific primers and probes (Table 3). Additional primers and probes were designed based on the published Saimiri sciureus sequences for IL-4, IL-5, IL-6, LTA and IFN- $\gamma$ (IL-4: GenBank DQ985388.1; IL-5: GenBank AF294756.1; IL-6: GenBank AF294757.1 and LTA: GenBank FJ589021.1). The gene expression of IL-4, IL-5, IL-6 and LTA was also assessed through real-time PCR using Custom Taq$\mathrm{Man}^{\bullet}$ Gene Expression Assays (Table 3).

In order to evaluate the analysis of gene expression of cytokines, it was used a total of nine Saimiri (V17, V31, 24, 149, 51, S8, S34, S36 and PA51) and one human blood samples. RNA was extracted from triplicate wells of PBMC and splenocytes using the PureLink RNA Mini Kit (Ambion, Inc.) according to the manufacturer's instructions. Reverse transcription was performed using High Capacity cDNA Reverse Transcription (Applied Biosystems). Briefly, $10 \mu$ l of each extracted RNA was added to $10 \mu \mathrm{l}$ of reaction mix containing $2 \mu \mathrm{l}$ of $10 \mathrm{x}$ RT buffer, $0.8 \mu \mathrm{l}$ of 25X dNTP Mix, $2 \mu$ l of 10X RT Random Primers, $1 \mu \mathrm{l}$ of MultiScribe ${ }^{\mathrm{rm}}$ Reverse Transcriptase and $4.2 \mu \mathrm{l}$ of nuclease-free water. The thermal cycling conditions consisted of $25^{\circ} \mathrm{C}$ for $10 \mathrm{~min}, 37^{\circ} \mathrm{C}$ for $120 \mathrm{~min}$ and $85^{\circ} \mathrm{C}$ for $5 \mathrm{~min}$.

Each well of the TaqMan ${ }^{\oplus}$ Array Plate was reconstituted using $10 \mu \mathrm{l}$ of TaqMan ${ }^{\bullet}$ Gene Expression Master Mix (Applied Biosystems) and $10 \mu \mathrm{l}$ of template cDNA. For custom assays, $9 \mu \mathrm{l}$ of template cDNA was added in a $20-\mu \mathrm{l}$ reaction volume containing $1 \mu \mathrm{l}$ of the 20x TaqMan Gene Expression Assay Mix and $10 \mu \mathrm{l}$
Table 3 Assays identifications for the genes used in real-time PCR using inventoried and custom TaqMan Gene Expression Assays

\begin{tabular}{|c|c|}
\hline Gene & ID \\
\hline \multicolumn{2}{|c|}{ Inventoried Assays } \\
\hline $18 \mathrm{~S}$ & Hs99999901_s1 \\
\hline GAPDH & Hs99999905_m1 \\
\hline HPRT1 & Hs99999909_m1 \\
\hline GUSB & Hs99999908_m1 \\
\hline IFNA1 & Hs00855471_g1 \\
\hline IFNA16 & Hs03005057_sH \\
\hline IFNA17 & Hs00819693_sH \\
\hline IFNA2 & Hs02621172_s1 \\
\hline IFNA6 & Hs00819627_s1 \\
\hline IFNA7 & Hs01652729_s1 \\
\hline IFNA8 & Hs00932530_s1 \\
\hline IFNB1 & Hs00277188_s1 \\
\hline IFNG & Hs00989291_m1 \\
\hline IL-10 & Hs00961622_m1 \\
\hline $\mathrm{IL}-12 \mathrm{~A}$ & Hs01073447_m1 \\
\hline IL-12B & Hs01011518_m1 \\
\hline IL-13 & Hs99999038_m1 \\
\hline IL-15 & Hs01003716_m1 \\
\hline IL-16 & Hs00189606_m1 \\
\hline IL-17A & Hs00174383_m1 \\
\hline IL-18 & Hs99999040_m1 \\
\hline IL-1A & Hs00174092_m1 \\
\hline IL-1B & Hs01555410_m1 \\
\hline IL-2 & Hs00174114_m1 \\
\hline IL-3 & Hs00174117_m1 \\
\hline $\mid \mathrm{L}-4$ & Hs00174122_m1 \\
\hline IL-5 & Hs00174200_m1 \\
\hline IL-6 & Hs00985639_m1 \\
\hline IL-8 & Hs99999034_m1 \\
\hline IL-9 & Hs00174125_m1 \\
\hline LTA & Hs00236874_m1 \\
\hline TNF & Hs00174128_m1 \\
\hline \multicolumn{2}{|c|}{ Custom Assays } \\
\hline $\mathrm{IL}-4$ & AIWR2WR \\
\hline IL-5 & AlVI4QJ \\
\hline IL-6 & AlT96KB \\
\hline LTA & AIS08D3 \\
\hline IFNG & AIRR97V \\
\hline
\end{tabular}

of the 2x TaqMan Gene Expression Master Mix. The reaction was performed using an Applied Biosystems real-time PCR 7500 System with the following cycling 
conditions: $50^{\circ} \mathrm{C}$ for $2 \mathrm{~min}$ and $95^{\circ} \mathrm{C}$ for $10 \mathrm{~min}$, followed by 40 cycles of $95^{\circ} \mathrm{C}$ for $15 \mathrm{sec}$ and $60^{\circ} \mathrm{C}$ for $60 \mathrm{sec}$. The calculation method used for relative quantification was the comparative $\mathrm{CT}$ method. The relative expression was determined as the expression of the corresponding genes in PBMC obtained from the healthy human donor or of the corresponding genes in unstimulated PBMC or splenocytes cultures.

\section{Results}

In the present study, the gene expression of cytokines from Saimiri was analysed in PBMC stimulated with PMA and ionomycin. The cross-reactivity of human cytokine antibodies for cytokines secreted by Saimiri cells was evaluated using Luminex, CBA, ELISA, ELISPOT, and ICS. For all employed assays, the mononuclear cells were stimulated using mitogens, and human cells or the supernatants obtained from human cells were used as controls.

\section{Human and non-human BD cytometric bead array Th1/Th2 cytokine kit}

The CBA assays were used to analyse the secretion of cytokines (IL-2, IL-4, IL-5, IL-6, IL-10, TNF, and IFN- $\gamma$ ) in PBMC cultures from five Saimiri monkeys and one human donor. As expected, upon in vitro stimulation of human mononuclear cells with PMA/ionomycin, increased cytokine secretion was observed in the supernatants of stimulated cells compared to unstimulated cultures (Figure 1). However, the use of both human and non-human CBA kits facilitated the detection of only IL-2 in the supernatants of cell cultures from Saimiri, even after $6 \mathrm{hrs}$ of stimulation with mitogens (Figure 1).

\section{Luminex}

The ability of Bio-Plex Pro Human Cytokine Th1/Th2 Assay Kit to detect S. sciureus IL-2, IL-4, IL-5, IL-10, IL-12, IL-13, GM-CSF, IFN- $\gamma$ and TNF cytokines was tested using

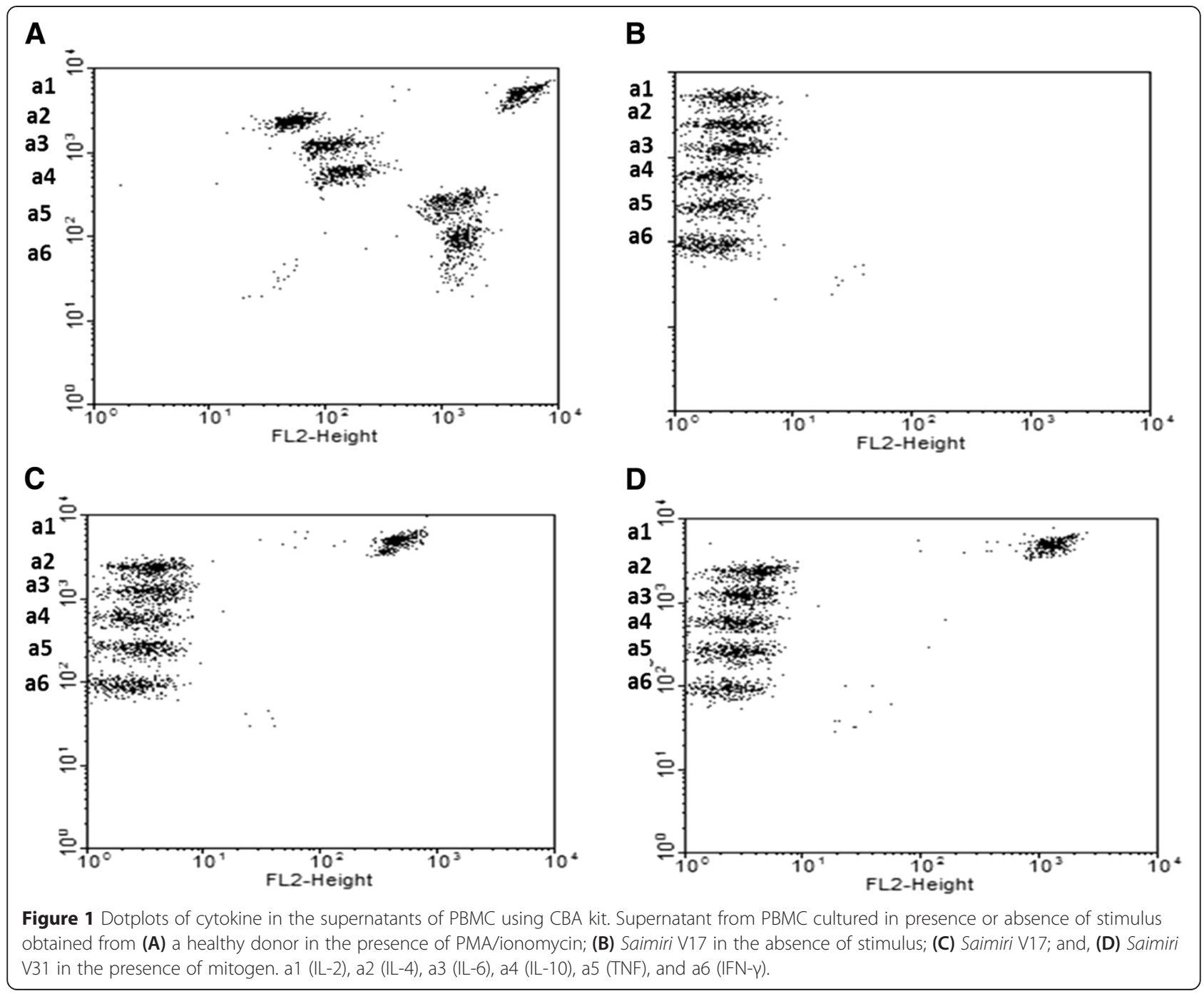


supernatant samples from PBMC isolated from two monkeys and one healthy donor after stimulation with PMA/ionomycin for 6, 12, 18, 24, 48, 72 and 96 hrs. As expected, Luminex assay was able to detect all evaluated cytokines in the supernatants from mitogenic stimulated-human PBMC (Figures 2 and 3). The higher responses for each cytokine were: $12 \mathrm{hrs}$ for IL-2; 48 hrs for IL-4, IL-10, IL-12, IL-13 and IFN- $\gamma ; 72$ hrs for TNF and; 96 hrs for IL-5 and GM-CSF. In contrast, only IL-2 was detected in the supernatant of PBMC cultures isolated from Saimiri V31 and V17, showing higher levels after $48 \mathrm{hrs}$ and $96 \mathrm{hrs}$, respectively (Figure 3).

\section{ELISA and ELISPOT assays}

The cross-reactivity of anti-human cytokines antibodies with cytokine produced by Saimiri stimulated PBMC was also evaluated by ELISA and ELISPOT.

ELISA and ELISPOT assays for the detection of TNF, IFN- $\gamma$, IL-4, IL-5, IL-10, and IL-13 were performed using fresh PBMC isolated from ten Saimiri monkeys and one healthy human donor. Table 1 shows the information for the human-specific antibodies used to test for reactivity in $S$. sciureus cells. In both ELISPOT and ELISA assays, only anti-human antibodies from Mabtech suppliers facilitated the measurement of IFN- $\gamma$ (mAb GZ-4 and 7-B6-1 clones) and
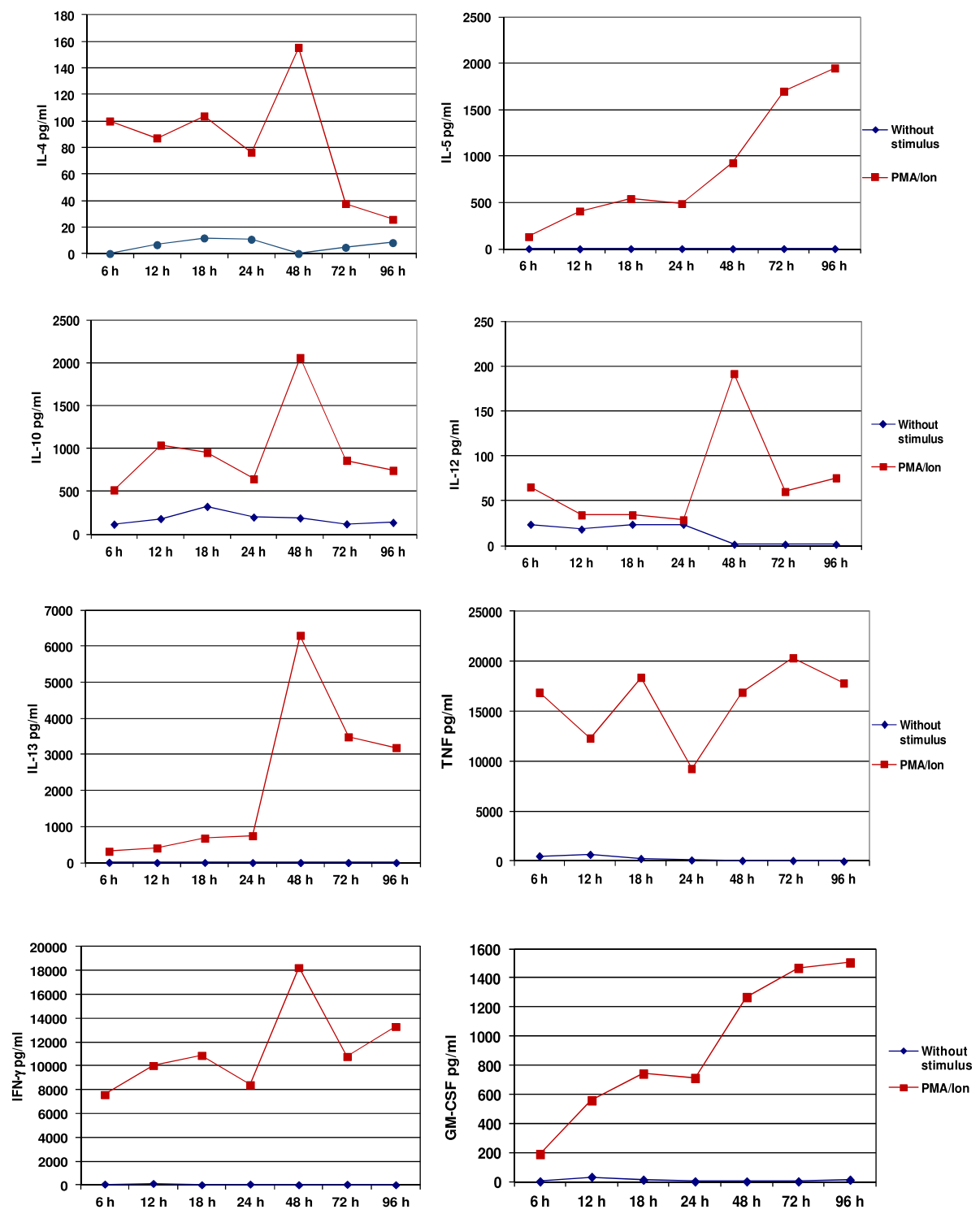

Figure $\mathbf{2}$ Cytokine concentrations in the supernatant of PBMC using the Luminex assay. The samples were obtained from PBMC isolated from a healthy human donor and cultured in the presence or absence of mitogenic stimulus. 

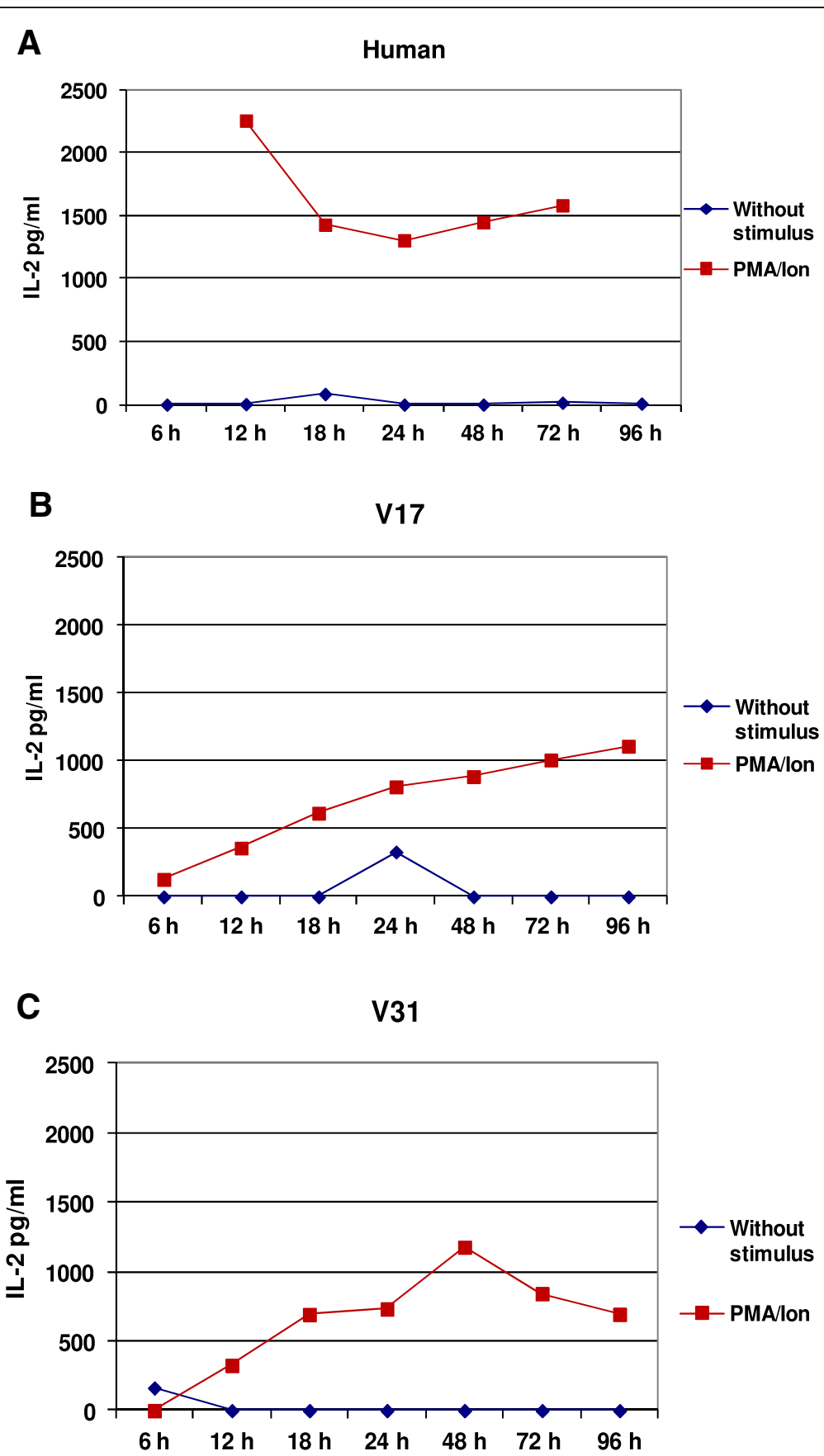

Figure $\mathbf{3}$ Detection of IL-2 in the supernatant of PBMC from Saimiri sciureus using Luminex assay. IL-2 concentration in the supernatant of cells cultured in the presence or absence of mitogenic stimulus from (A) a healthy human donor and (B and C) two Saimiri sciureus (V17 and V31) samples.

IL-4 (mAb IL4-I and mAb IL4-II clones) in both PBMC cultures and the supernatant obtained from cultured S. sciureus cells (Table 1). The results containing the numbers of SFU in ELISPOT assays and the optical densities (O.D.) values obtained in ELISA for IFN- $\gamma$ and IL- 4 are represented in Figure 4.
ICS assay

The ICS assay was performed using human monoclonal antibodies for IL-4, IL-5, IL-10, IL-13, IFN- $\gamma$, and TNF and the positivity was determinate setting the region of cytokine-producing lymphocytes using mitogen stimulated and non-stimulated human PBMC cultures. However, only 


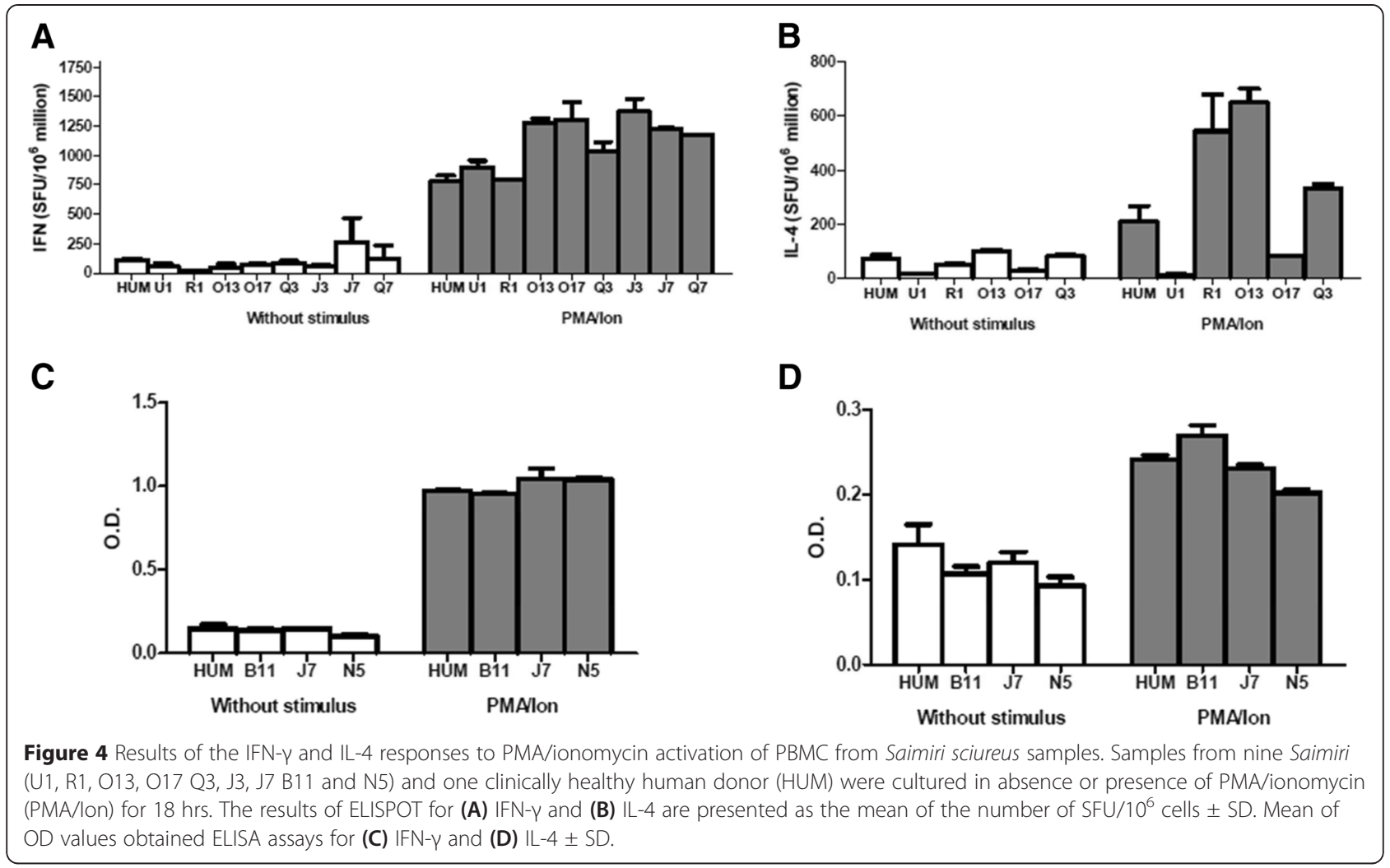

the anti-IFN- $\gamma$ (clones mAb GZ-4 and 7-B6-1) human antibodies from Mabtech supplier facilitated the detection of this cytokine in both human and NHP cells (Table 2).

\section{Gene expression using real-time PCR}

In the first experiment, PBMC from two Saimiri (V17 and V31) samples and one human sample were cultured in the presence or absence of PMA/ionomycin for 6,12 , 24, 48 and 72 hrs. Gene expression analysis was performed using TaqMan ${ }^{\oplus}$ Gene Expression Array Plates. A total of 12 of the 28 cytokines assayed were detected in NHP samples, including IL-1A, IL-2, IL-4, IL-5, IL-6, IL10, IL-12B, IL-17, IFN- $\beta$, IFN- $\gamma$, LTA, TNF, and two housekeeping genes. However, only seven cytokines (IL$1 \mathrm{~A}$, IL-2, IL-10, IL-12B, IL-17, IFN- $\beta$, and TNF) presented relative expression of at least $70 \%$ of the corresponding genes in PBMC culture obtained from the healthy human donor (Figure 5). As expected, the gene expression of the 28 cytokines and four housekeeping genes in PBMC from the human donor was readily detected.

In the second experiment, PBMC from three Saimiri $(24,149$ and 51) samples and PBMC obtained from one human blood sample were cultured in the presence or absence of PMA/ionomycin for 12, 24 and 48 hrs. Gene expression analysis using primers and probes for IL-4, IL-5, IL-6, LTA, and IFN- $\gamma$ was performed using the
Custom TaqMan Gene Expression Assay with primer sets specifically designed based on Saimiri sequences. The results revealed the gene expression levels of the five cytokines in PBMC from Saimiri, whereas no gene expression was detected in human PBMC (Figure 6).

In order to confirm the results obtained in the first and second experiments, in the third experiment, PBMC from three Saimiri (S8, S34 and S36) samples and from

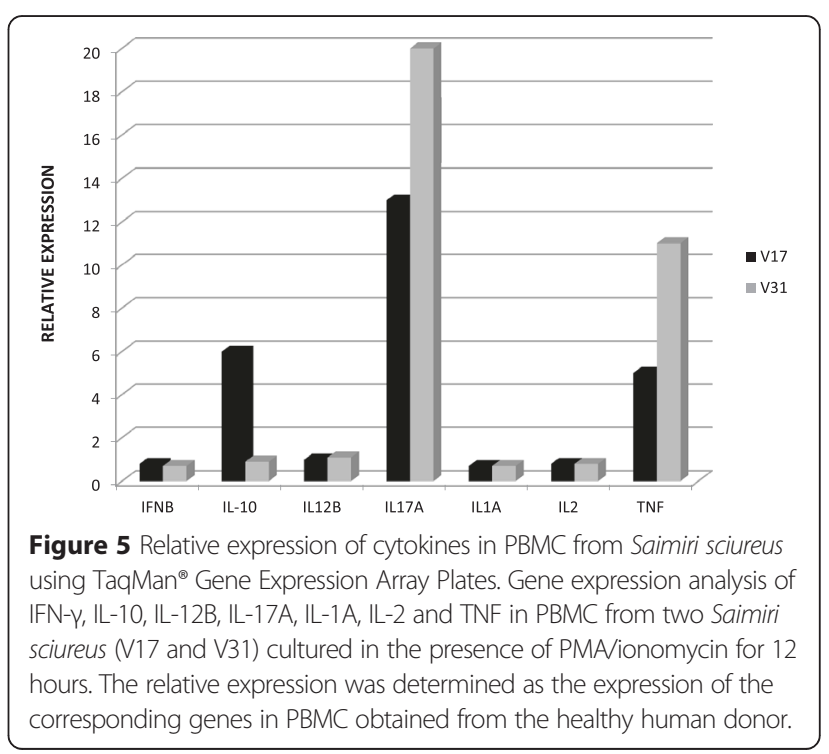



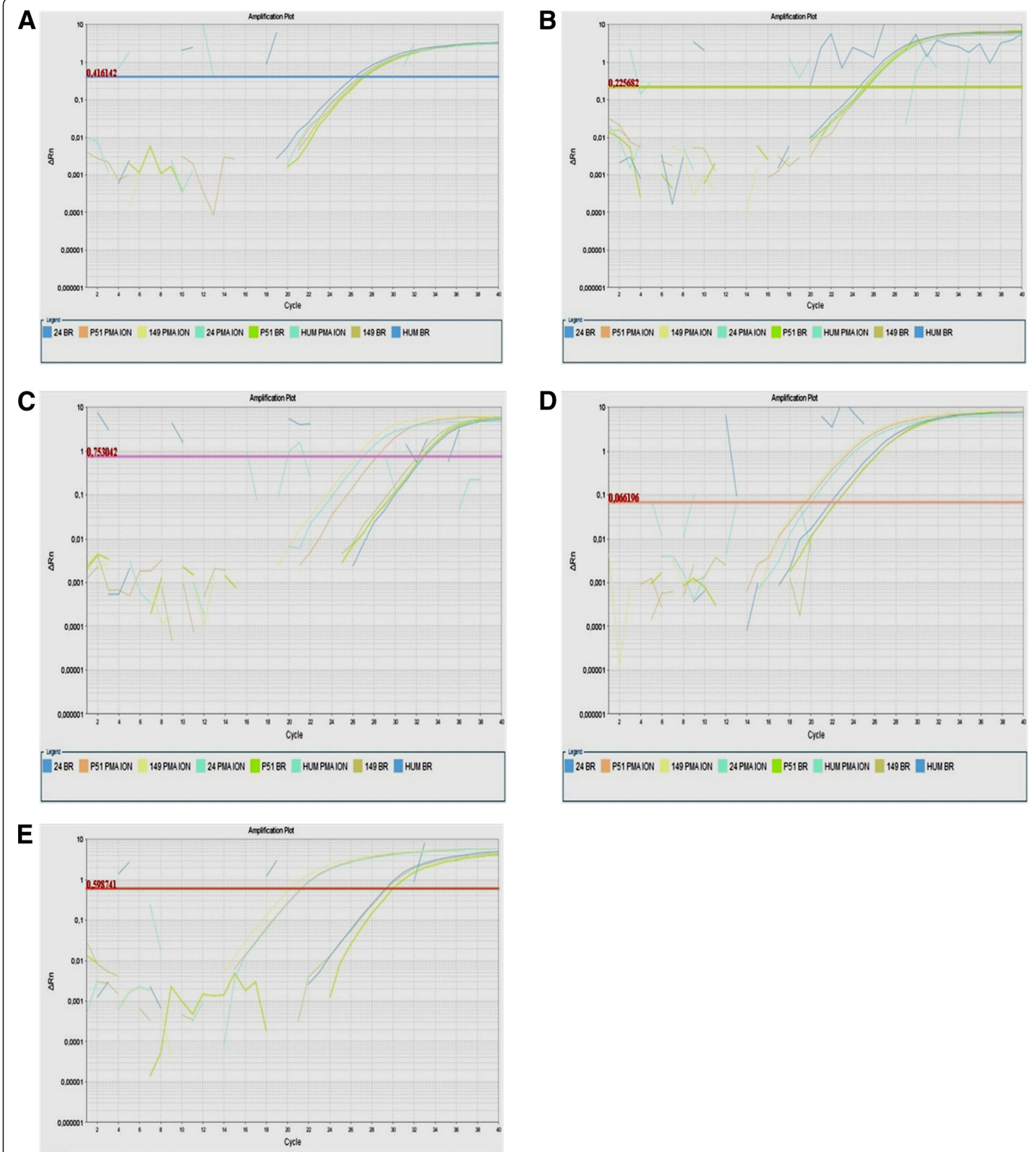

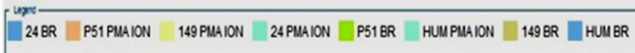

Figure 6 Plots showing real-time PCR amplification using custom TaqMan ${ }^{\circledR}$ Gene Expression Assays. Samples from three Saimiri sciureus (24, P51 and 149) and one human health donor (HUM) were cultured in absence (BR) or presence of PMA/ionomycin (PMA ION) for 12 h. Delta Rn versus cycle amplification plots were obtained using primers and probes for (A) IL-4, (B) IL-5, (C) IL-6, (D) LTA, and (E) IFN- $\gamma$. The lines represent the threshold. 
one human donor sample were cultured in the presence or absence of PMA/ionomycin for 12, 24 and $48 \mathrm{hrs}$. Gene expression of IFN- $\gamma$, IL-10, IL-12B, IL-17A, IL-1A, IL-2 and TNF was assessed using TaqMan Gene Expression Plates and the gene expression of IL-4, IL-5, IL-6, LTA, and IFN- $\gamma$ was assessed using Custom TaqMan Gene Expression Assay. The TaqMan Gene Expression Plates facilitated the detection of the gene expression of IL-1A, IL-2, IL-10, IL-12B, IL-17, IFN- $\beta$, and TNF in PBMC from Saimiri, showing a relative expression of at least $70 \%$ of the gene expression observed in the PBMC obtained from the human donor in the presence of PMA/ionomycin (Figure 7). Similarly, the Custom TaqMan Gene Expression Assay revealed the gene expression of IL-4, IL-5, IL-6 LTA, and IFN- $\gamma$, although expression of these genes was not detected in human PBMC (Figure 8).

In the fourth experiment, PBMC and splenocytes obtained from one Saimiri (PA51) sample were cultured in the presence or absence of PMA/ionomycin for 3, 6, 12, 24, 48 and $72 \mathrm{hrs}$, and the gene expression was analysed using TaqMan Gene Expression Plates and the Custom TaqMan Gene Expression Assay. The relative expression was determined as the expression of the corresponding genes in unstimulated PBMC or splenocytes cultures. Gene expression of IL-1A, IL-2, IL-10, IL-12B, IL-17, IFN- $\beta$, and TNF was detected using the plates, and the Custom TaqMan Gene Expression Assay revealed the gene expression of IL-4, IL-5, IL-6 LTA, and IFN- $\gamma$ in both PBMC and splenocytes from Saimiri. Furthermore, the results showed that the optimal time point for the evaluation of gene expression for the studied cytokines was at 6-12 hrs after culture, with the exception of LTA

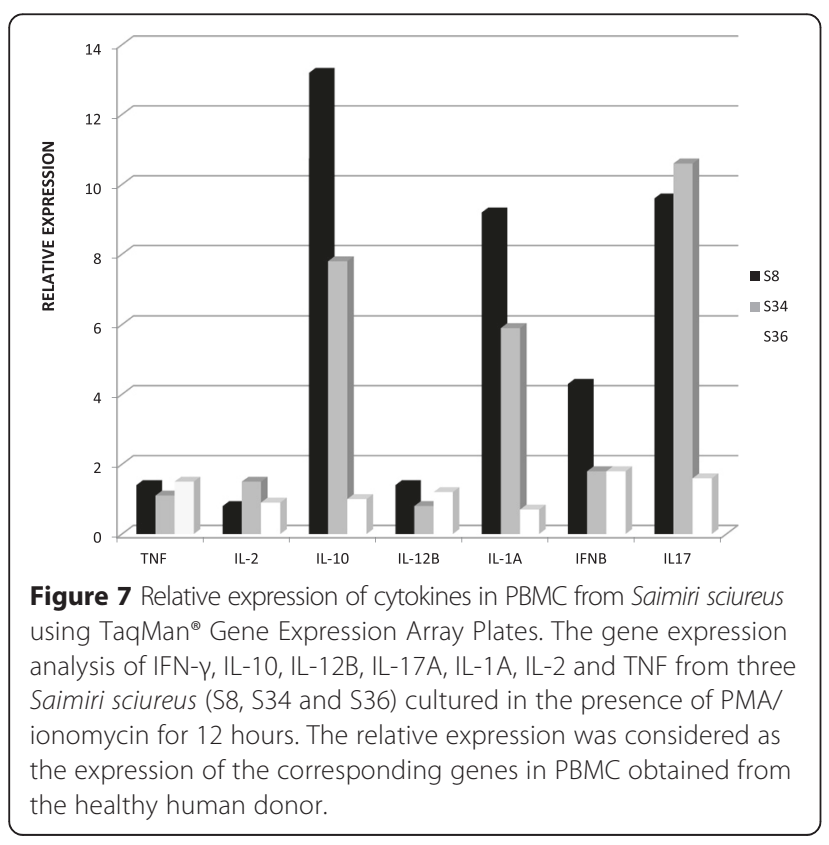

in PBMC, which exhibited optimal expression after 24 hrs of culture (Figure 9).

\section{Discussion}

Malaria remains a serious public health problem and the most important parasitic disease in developing countries in tropical regions [35]. The development of an effective vaccine represents an important measure for disease control, as this treatment approach would be preventative. For effective vaccine development, it is essential to understand the mechanisms underlying the acquisition of malaria immunity in humans [36-39]. However, studies in humans are complex and beyond ethical limitations $[40,41]$, and many other limitations, such as the lack of access to relevant organ and tissue samples and the difficulty to manipulate the immune response, make the use of experimental models necessary. Therefore, the use of experimental models phylogenetically related to humans is ideal. Indeed, the WHO has recommended the use of neotropical primates of the genus Aotus and Saimiri for experimental studies on malaria [17].

Notwithstanding these benefits, there are restrictions to the use of these animals, and the lack of specific reagents represents an important constraining factor. Therefore, the development and use of immunological and molecular tools could facilitate the reliable evaluation of the immune response in preclinical trials of malaria vaccines and mediate the characterization of the pathogenesis of disease in these animals [42-45].

Cytokines secreted from cells of the immune system play essential roles during malaria [46]. Thus, specific reagents and assays for the detection and quantification of these molecules could provide information concerning the immunological and physio-pathological changes that occur during experimental infection of these animals.

Other studies involving Saimiri and Aotus have previously been conducted for the development of molecular reagents. Several genes encoding molecules involved in the immune response, such as cytokines, Duffy blood factor, $\mathrm{T}$ cell immunoglobulin receptor, and Toll-like receptors, have been sequenced, and these results have shown greater than $80 \%$ identity to the human counterparts. For instance, degrees of identity between 91.4 and 98.1\% for the sequences of IL-1 $\beta$, IL-2, IL-5, IL-6, IL-10, IFN- $\gamma$, and TNF from S. sciureus and other NHP and humans were observed [30]. These data suggest that human sequences as templates for the design of Saimirispecific primers and probes may be used to obtain amplification products to study cellular immune responses in Saimiri and Aotus $[33,47,48]$.

In the present study, molecular and immunological tools were developed to evaluate the immune response of the 

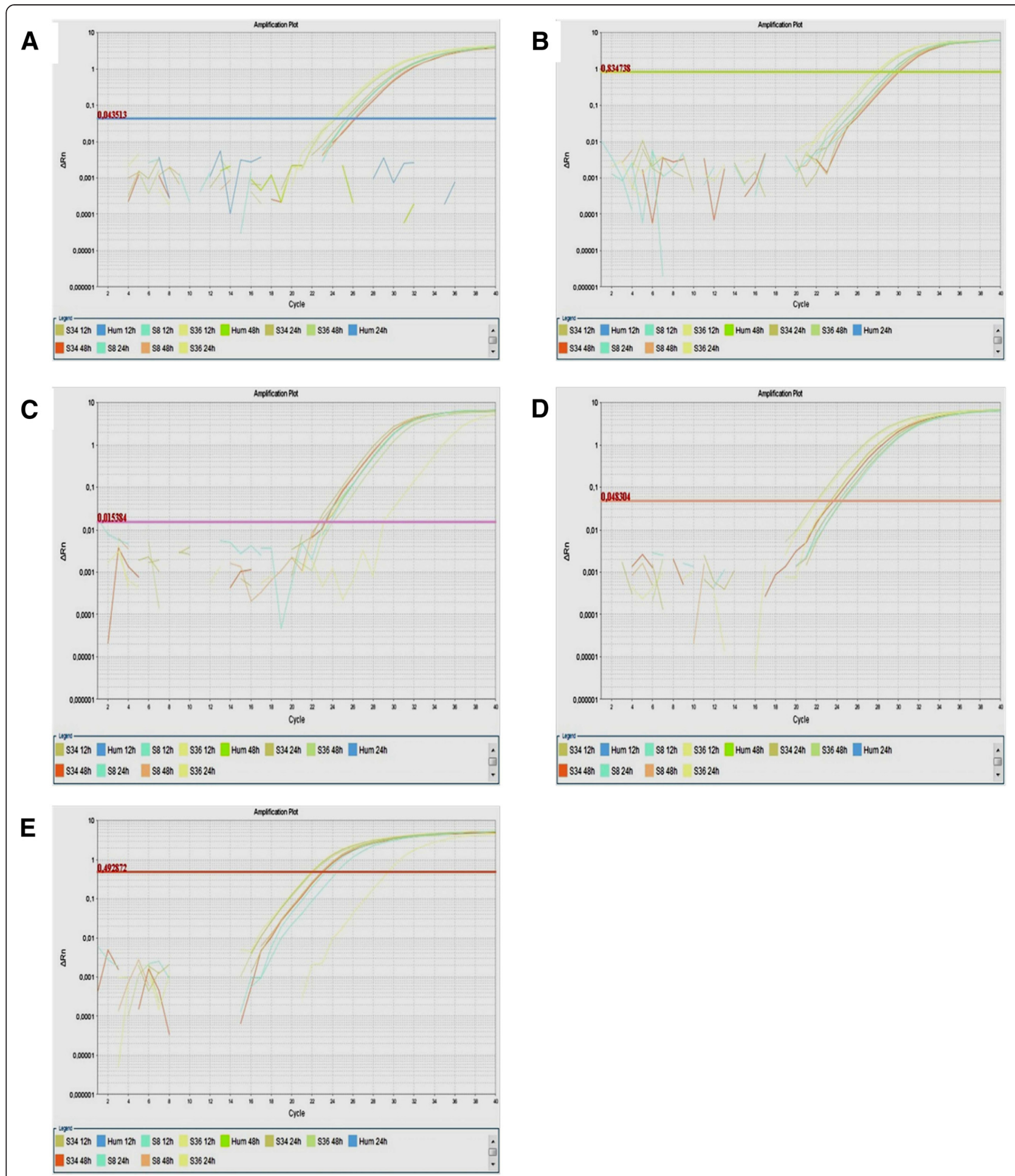

Figure 8 Plots showing real-time PCR amplification using custom TaqMan ${ }^{\oplus}$ Gene Expression Assays. Samples from three Saimiri sciureus (S8, S36 and S34) and one healthy human donor (HUM) were cultured in absence (BR) or presence of PMA/ionomycin (PMA ION) for 12 h, 24 and 48 h. Delta $R n$ versus cycle amplification plots were obtained using primers and probes for (A) IL-4, (B) IL-5, (C) IL-6, (D) LTA, and (E) IFN- $\gamma$. The lines represent the threshold. 


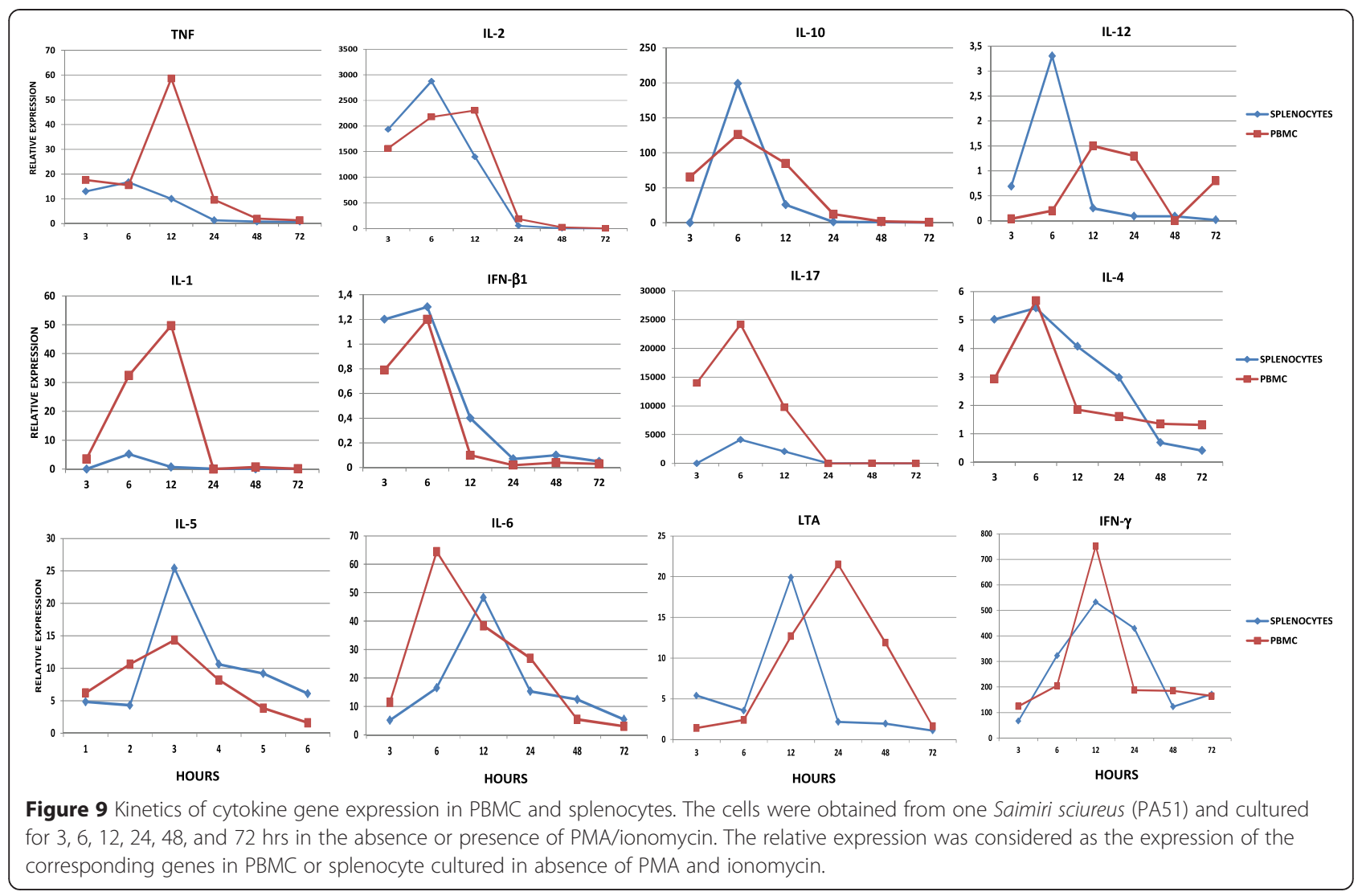

NHP S. sciureus using human and non-human CBA, Luminex, ELISA, ELISPOT, ICS, and real-time PCR assays.

The use of five assays specific for humans (CBA, Luminex, ELISA, ELISPOT and ICS) facilitated the detection of a limited number of cytokines in NHP, including IL-2 in humans and NHP with CBA and Luminex, IL-4 and IFN- $\gamma$ with ELISPOT and ELISA and IFN- $\gamma$ with ICS. These findings may reflect the reduced specificity of human monoclonal antibodies to Saimiri cytokines. A previous study reported difficulty in detecting TNF from Old World monkeys using commercial enzyme-linked immunoassay kits designed for the detection and quantification of human TNF [49]. It was suggested that the 62- to 72-amino acid region of TNF might contribute to the specificity of monoclonal antibodies to this cytokine in humans. Furthermore, this region in the Saimiri sequence is highly divergent, with six substitutions and the addition of a glutamine residue at position 62 . These alterations may reduce the cross-reactivity of monoclonal antibodies with Saimiri TNF, a fact that should be considered when using this antibody for the detection and quantification of TNF from Saimiri sciureus. The effect of small sequence differences in the recognition of orthologous molecules in different species has also been illustrated in studies showing that the injection of recombinant human cytokines in NHP induced potent neutralizing antibody responses against these cytokines, even considering the high homologies (>95\%) in the peptide and nucleotide sequences [28]. Differences in the sequences and conformations might also explain the results previously obtained by using a panel of 67 monoclonal antibodies from different manufacturers to define the reactivity of these molecules against $C D$ markers in Saimiri mononuclear cells [50]. In some cases, adequate reactivity was observed, with variation in the intensity of staining depending on the clone and manufacturer used, although in many cases no reactivity was detected. Similarly, one study tested 204 antibodies against various human CD markers, and only $28 \%$ of these molecules reacted with Aotus splenocytes [51]; approximately $40 \%$ of the reacting antibodies also recognized rhesus and cynomolgus cells. The use of NHP CBA only facilitated the detection of IL-2, reflecting the broader specificity of antibodies to human cytokines that also cross-react with rhesus, cynomolgus, baboon and pig-tailed macaque cytokines. These findings highlight the need for the development of immunological tools for cytokine detection in S. sciureus.

Gene expression of cytokines in cell cultures from $S$. sciureus was evaluated. First, gene expression analysis was performed using TaqMan ${ }^{\circledast}$ Gene Expression Array 
Plates containing predesigned primers and probes for the detection of 28 human cytokine transcripts. These results revealed the detection of 12 (IL-1A, IL-2, IL-4, IL-5, IL-6, IL-10, IL-12B, IL-17, IFN- $\beta$, IFN- $\gamma$, LTA, and TNF) of the 28 cytokines and two housekeeping genes. However, only seven (IL-1A, IL-2, IL-10, IL-12, IL-17, IFN- $\beta$, and TNF) of these cytokines presented a relative quantification of at least $70 \%$ of the gene expression observed in human cells after mitogenic stimulation. The failure in the amplification of some cytokines may reflect the partial similarity between sequences in Saimiri and the corresponding genes in humans [33]. However, when comparing the mRNA sequences for the cytokines from $S$. sciureus obtained from GenBank with human sequences using the Basic Local Alignment Search Tool (BLAST), similar degrees of identity between the amplified and nonamplified cytokines were observed. For example, the degree of identity for the genes encoding IL-4 (not amplified) and TNF (amplified) between humans and S. sciureus was $92 \%$. Thus, the failure in the amplification of some cytokines most likely reflects small changes in the existing sequences between the human gene and the corresponding Saimiri gene, leading to an imperfect annealing of the primer to the DNA template.

Among the 12 cytokines initially amplified, five (IL-4, IL-5, IL-6, LTA, and IFN- $\gamma$ ) showed relative expression levels below the threshold of $70 \%$ of the gene expression observed in human cells. However, when primers and probes specific for $S$. sciureus were designed from the published sequences in GenBank, it was possible to detect these cytokine transcripts in mononuclear cells from S. sciureus, highlighting the need for the design and use of specific reagents for use with these models, as small differences in sequences can result in difficulties or even preclude proper annealing.

Moreover, PBMC and splenocytes from one S. sciureus sample were cultured in the presence or absence of stimuli classically used to stimulate cells in vitro (PMA/ ionomycin) since Ag specific stimuli would not be broad enough to a detectable activation of cells for $3,6,12$, 24, 48 , and $72 \mathrm{hrs}$ to evaluate the kinetics of IL-1A, IL-2, IL-4, IL-5, IL-6, IL-10, IL-12B, IL-17A, TNF, IFN- $\beta$, LTA, and IFN- $\gamma$ expression. The results demonstrated the gene expression of these cytokines in both PBMC and splenocytes cultures. Furthermore, the results showed that the cytokine transcripts were detected after 6 and 12 hrs of culture, showing the detection of IL-2, IL-6, IL10, IL-12, IFN- $\gamma$, TNF, and LTA transcripts after $6 \mathrm{hrs}$ of Saimiri PBMC culture in the presence of PMA/ionomycin. These results are in agreement with a previous report showing similar patterns of gene expression of these cytokines upon PMA/ionomycin stimulation of Saimiri splenocytes using Saimiri-specific primers in SYBR-greenbased real time PCR assays [52].
Unfortunately, cytokines IL-1B, IL-3, IL-8, IL-9, IL-12A, IL-13, IL-15, IL-16, IL-18, IFN- $\alpha 1$, IFN- $\alpha 2$, IFN- $\alpha 6$, IFN- $\alpha$ 7, IFN- $\alpha 8$, IFN- $\alpha 16$, or IFN- $\alpha 17$ were not successfully amplified. Amplification of these genes therefore requires additional effort to define primers and probes, as the sequences for these genes in S. sciureus have not been published.

\section{Conclusions}

In the present study, a variety of techniques to extend the range of reagents available for NHP research, with the aim of facilitating a more thorough evaluation of the immune response in the Saimiri sciureus experimental model of human Plasmodium infection was assessed. The data presented herein validate the approach used for the extension of the available reagent range, facilitating a more thorough evaluation of the immune response in this model.

\section{Competing interests}

The authors declare that they have no competing interests.

\section{Authors' contributions}

EKPR and LRPR participated in the study design, performed the experiments and wrote the manuscript; CBJ, PRRT and VS performed the experiments and reviewed the manuscript; CTDR and LJMC conceived the study, participated in the study design and reviewed the manuscript. All authors have read and approved the final manuscript.

\section{Acknowledgements}

This study was supported through funding from the Programa de Desenvolvimento Tecnológico em Insumos para Saúde (PDTIS/Fiocruz), the Programa de Apoio a Núcleos de Excelência (Pronex) [Departamento de Ciência e Tecnologia (DECIT) do Ministério da Saúde do Brasil, Conselho Nacional de Desenvolvimento Científico e Tecnológico (CNPq, Brazil) and Fundação de Amparo à Pesquisa do Estado do Rio de Janeiro (FAPERJ)], the Neglected Disease Program from FAPERJ, and the Instituto Oswaldo Cruz (Fiocruz, Brazil) POM grants. VS was supported by a Sanofi-Pasteur sponsorship. CTDR and LJMC are recipients of a Research Productivity Fellowship from the CNPq. CTDR also received a grant from FAPERJ as a "Cientista do Nosso Estado".

\section{Author details}

'Laboratório de Pesquisa em Malária, Instituto Oswaldo Cruz, Fiocruz, Avenida Brasil 4365, Pavilhão Leônidas Deane, Salas 513-517, $5^{\circ}$ andar Manguinhos, Rio de Janeiro, RJ CEP: 21040-900, Brazil. ' Centro de Pesquisa, Diagnóstico e Treinamento em Malária (CPD-Mal), Fiocruz, Reference Centre for Malaria in the Extra-Amazonian Region for the Secretary for Health Surveillance, Ministry of Health, Rio de Janeiro, RJ, Brazil. ${ }^{3}$ Present address: Research

Department, Sanofi Pasteur, Lyon, France.

Received: 6 November 2014 Accepted: 10 April 2015 Published online: 18 April 2015

\section{References}

1. MacDonald DM, Holmes EC, Lewis JCM, Simmonds PJ. Detection of hepatitis $B$ virus infection in wild-born chimpanzees (Pan troglodytes verus): phylogenetic relationships with human and other primate genotypes. J Virol. 2000;74:4253-7.

2. Makuwa M, Souquiere S, Clifford SL, Mouinga-Ondeme A, Bawe-Johnson M, Wickings EJ. Identification of hepatitis B virus genome in faecal sample from wild living chimpanzee (Pan troglodytes troglodytes) in Gabon. J Clin Virol. 2005;34:83-8.

3. Carcamo WC, Nguyen CQ. Advancement in the development of models for hepatitis C research. J Biomed Biotechnol. 2012;2012:346761.

4. Dupinay T, Gheit T, Roques P, Cova L, Chevallier-Queyron P, Tasahsu SI, et al. Discovery of naturally occurring transmissible chronic hepatitis $B$ virus 
infection among Macaca fascicularis from Mauritius Island. Hepatology. 2013;58:1610-20.

5. Li T, Zhu S, Shuai L, Xu Y, Yin S, Bian Y, et al. Infection of common marmosets with hepatitis $C$ virus/GB virus-B chimeras. Hepatology. 2014,59:789-802

6. Staprans SI, Feinberg MB. The roles of nonhuman primates in the preclinical evaluation of candidate AIDS vaccines. Expert Rev Vaccines. 2004;3:S5-32.

7. Morgan C, Marthas M, Miller C, Duerr A, Cheng-Mayer C, Desrosiers R, et al. The use of nonhuman primate models in HIV vaccine development. PLoS Med. 2008;5:e173.

8. Singh S, Nehete P, Hanley P, Nehete B, Yang G, He H, et al. Procedures for mucosal immunization and analyses of cellular immune response to candidate HIV vaccines in murine and nonhuman primate models. Methods Mol Biol. 2014;1184:417-55.

9. Gardner MB, Luciw PA. Macaque models of human infectious disease. ILAR J. 2008:49:220-55.

10. Good MF. The hope but challenge for developing a vaccine that might control malaria. Eur J Immunol. 2009;39:939-43.

11. Wykes MN, Good MF. What have we learnt from mouse models for the study of malaria? Eur J Immunol. 2009;39:2004-7.

12. Langhorne J, Buffet P, Galinski M, Good M, Harty J, Leroy D, et al. The relevance of non-human primate and rodent malaria models for humans. Malar J. 2011;10:23.

13. Teixeira C, Gomes R. Experimental models in vaccine research: malaria and leishmaniasis. Braz J Med Biol Res. 2013;46:109-16.

14. Krief S, Escalante AA, Pacheco MA, Mugisha L, André C, Halbwax M. On the diversity of malaria parasites in African apes and the origin of Plasmodium falciparum from Bonobos. PLoS Pathog. 2010;6:e1000765.

15. Prugnolle F, Ollomo B, Durand P, Yalcindag E, Arnathau C, Elguero E. African monkeys are infected by Plasmodium falciparum nonhuman primate-specific strains. Proc Natl Acad Sci U S A. 2011;108:11948-53.

16. Sharp PM, Liu W, Learn GH, Rayner JC, Peeters M, Hahn BH. Source of the human malaria parasite Plasmodium falciparum. Proc Natl Acad Sci U S A. 2011;108:744-5.

17. WHO. Role of non-human primates in malaria vaccine development: memorandum from WHO meeting. Bull World Health Organ. 1988;66:719-28.

18. Kennedy RC, Shearer MH, Hildebrand WH, Simmonds RS. Non-human primates and their potential use in immunologically based investigations. The Immunologist. 1997;5:150-6.

19. Reynolds J. Report on the biomedical primate research center. Annual resource guide. Primate supply information clearinghouse. US: Washington Regional Primate Research Center; 2001.

20. Bailey J. Non-human primates in medical research and drug development: a critical review. Biog Amines. 2005;19:235-55.

21. Carvalho LM, Oliveira SG, Alves FA, Brígido MCO, Muniz JAPC, Daniel-Ribeiro CT. Aotus infulatus monkey is susceptible to Plasmodium falciparum and may constitute an alternative experimental model for malaria. Mem Inst Oswaldo Cruz. 2000;95:363-5.

22. Herrera S, Perlaza BL, Bonelo A, Arévalo-Herrera M. Aotus monkeys: their great value for anti-malaria vaccines and drug testing. Int J Parasitol. 2002;32:1625-35.

23. Carvalho LMM, Alves FA, Oliveira SG, Valle RR, Fernandes AAM, Muniz JAPC. Severe anemia affects both splenectomized and non-splenectomized Plasmodium falciparum-infected Aotus infulatus monkeys. Mem Inst Oswaldo Cruz. 2003:98:679-86

24. Carvalho $\sqcup$, Oliveira SG, Theisen M, Alves FA, Andrade MC, Zanini GM, et al. Immunization of Saimiri sciureus monkeys with Plasmodium falciparum merozoite surface protein-3 and glutamate-rich protein suggests that protection is related to antibody levels. Scand J Immunol. 2004;59:363-72.

25. Carvalho LJ, Alves FA, Bianco Jr C, Oliveira SG, Zanini GM, Soe S, et al. Immunization of Saimiri sciureus monkeys with a recombinant hybrid protein derived from the Plasmodium falciparum antigen glutamate-rich protein and merozoite surface protein 3 can induce partial protection with Freund and Montanide ISA720 adjuvants. Clin Diagn Lab Immunol. 2005;12:242-8.

26. Arévalo-Herrera M, Vera O, Castellanos A, Céspedes N, Soto L, Corradin G, et al. Preclinical vaccine study of Plasmodium vivax circumsporozoite protein derived-synthetic polypeptides formulated in montanide ISA 720 and montanide ISA 51 adjuvants. Am J Trop Med Hyg. 2011;84:21-7.
27. Craig AG, Grau GE, Janse C, Kazura JW, Milner D, Barnwell JW, et al. The role of animal models for research on severe malaria. PLoS Pathog. 2012;8:e1002401.

28. Villinger F, Brar SS, Mayne A, Chikkala N, Ansari AA. Comparative sequence analysis of cytokine genes from human and nonhuman primates. J Immunol. 1995;155:3946-54

29. Delgado G, Parra-Lopez C, Spinel C, Patarroyo ML. Phenotypical and functional characterization of non-human primate Aotus spp dendritic cells and their use as a tool for characterizing immune response to protein antigens. Vaccine. 2005;23:3386-95.

30. Heraud JM, Lavergne A, Kazanji M. Molecular cloning, characterization, and quantification of squirrel monkey (Saimiri sciureus) Th1 and Th2 cytokines. Immunogenetics. 2002;54:20-9.

31. Hernández EC, Suárez CF, Méndez JA, Echeverry SJ, Murillo LA, Patarroyo ME. Identification, cloning and sequencing of different cytokine genes in four species of owl monkey. Immunogenetics. 2002;54:645-53.

32. Mérien F, Lavergne A, Behr C, Contamin H. Sequencing and analysis of genomic DNA and CDNA encoding TNF in squirrel monkey (Saimiri sciureus). Vet Immunol Immunopathol. 2003;92:37-43.

33. Alves FA, Souza MT, Gonçalves EC, Schneider MP, Marinho AM, Muniz JA, et al. DNA sequencing of 13 cytokine gene fragments of Aotus infulatus and Saimiri sciureus, two non-human primate models for malaria. Cytokine. 2010:52:151-5.

34. Walsh DS, Pichyangkul S, Gettayacamin M, Tongtawe P, Siegrist CA, Hansukjariya $P$, et al. Safety and immunogenicity of RTS, S + TRAP malaria vaccine, formulated in the AS02A adjuvant system, in infant Rhesus monkeys. Am J Trop Med Hyg. 2004;70:499-509.

35. WHO: World Malaria report 2013. http://www.who.int/malaria/publications/ world_malaria_report_2013/report/en/.

36. Miller LH, Baruch DI, Marsh K, Doumbo OK. The pathogenic basis of malaria. Nature. 2002;415:673-9.

37. Carvalho LJM, Daniel-Ribeiro CT, Goto H. Malaria vaccine: candidate antigens, mechanisms, constraints and prospects. Scand J Immunol. 2002;56:327-43

38. Lorenz $V$, Karanis $G$, Karanis P. Malaria vaccine development and how external forces shape it: an overview. Int J Environ Res Public Health. 2014;11:6791-807.

39. Barry $A E$, Arnott A. Strategies for designing and monitoring malaria vaccines targeting diverse antigens. Front Immunol. 2014;5:1-16.

40. Huang DT, Hadian M. Bench-to-bedside review: human subjects research - are more standards needed? Crit Care. 2006;10:244.

41. Legrand N, Weijer K, Spits H. Experimental models to study development and fuction of the human immune system in vivo. J of Immunol. 2006:176:2053-8.

42. Baruch DI, Gamain B, Barnwell JW, Sullivan JS, Stowers A, Galland GG, et al. Immunization of Aotus monkeys with a functional domain of the Plasmodium falciparum variant antigen induces protection against a lethal parasite line. Proc Natl Acad Sci U S A. 2002;99:3860-5.

43. Egan AF, Fabucci ME, Saul A, Kaslow DC, Miller LH. Aotus New World monkeys: models for studying malaria-induced anemia. Blood. 2002;99:3863-6.

44. Jones TR, Gramzinski RA, Aguiar JC, Sim BK, Narum DL, Fuhrmann SR, et al. Absence of antigenic competition in monkeys immunized with Plasmodium falciparum DNA vaccines delivered as a mixture. Vaccine. 2002;20:1675-80.

45. Lyon JA, Angov E, Fay MP, Sullivan JS, Girourd AS, Robinson SI, et al. Protection induced by Plasmodium falciparum MSP1 (42) is strain-specific, antigen and adjuvant dependent, and correlates with antibody responses. PLoS One. 2008;3:e2830.

46. Iriemenam NC, Okafor CM, Balogun HA, Ayede I, Omosun Y, Persson JO, et al. Cytokine profiles and antibody responses to Plasmodium falciparum malaria infection in individuals living in Ibadan, southwest Nigeria. Afr Health Sci. 2009;9:66-74.

47. Diaz D, Daubenberger CA, Zalac T, Rodriguez R, Patarroyo ME. Sequence and expression of MHC-DPB1 molecules of the New World monkey Aotus nancymaae, a primate model for Plasmodium falciparum. Immunogenetics. 2002;54:251-9.

48. Kazanji M, Heraud JM, Merien F, Pique C, de Thé G, Gessain A, et al. Chimeric peptide vaccine composed of $B$ - and T-cell epitopes of human T-cell leukemia virus type 1 induces humoral and cellular immune responses and reduces the proviral load in immunized squirrel monkeys (Saimiri sciureus). J Gen Virol. 2006;87:1331-7. 
49. Villinger F, Hunt D, Mayne A, Vuchetich M, Findley $H$, Ansari AA.

Qualitative and quantitative studies of cytokines synthesized and secreted by non-human primate peripheral blood mononuclear cells. Cytokine. 1993:5:469-79.

50. Contamin H, Loizon S, Bourreau E, Michel JC, Garraud O, Mercereau- Puijalon O, et al. Flow cytometry identification and characterization of mononuclear cell subsets in the neotropical primate Saimiri sciureus (squirrel monkey). J Immunol Methods. 2005:297:61-71.

51. Daubenberger CA, Spirig R, Patarroyo ME, Pluschke G. Flow cytometric analysis on cross-reactivity of human-specific CD monoclonal antibodies with splenocytes of Aotus nancymaae, a non-human primate model for biomedical research. Vet Immunol Immunopathol. 2007;119:14-20.

52. Alves FA, Pelajo-Machado M, Totino PRR, Souza MT, Gonçalves EC, Schneider MPC, et al. Splenic architecture disruption and parasite-induced splenocyte activation and anergy in Plasmodium falciparum -infected Saimiri sciureus monkeys. Malar J. 2015;14:128.

\section{Submit your next manuscript to BioMed Central and take full advantage of:}

- Convenient online submission

- Thorough peer review

- No space constraints or color figure charges

- Immediate publication on acceptance

- Inclusion in PubMed, CAS, Scopus and Google Scholar

- Research which is freely available for redistribution 